\title{
The effect of the roadway excavation disturbance by spacing between deep adjacent tunnels
}

\author{
ZHANG Ning ${ }^{1,2, a}$, GAO Ming-zhong ${ }^{1, b}$ and JING Lai-wang ${ }^{2, c}$ \\ ${ }^{1}$ School of Energy and Safety, Anhui University of Science and Technology, Huainan232001, China; \\ ${ }^{2}$ School of Science, Anhui University of Science and Technology, Huainan232001, China. \\ azh_nin@sina.com, ${ }^{\mathrm{b}} \mathrm{mzgao@aust.edu.cn,} \mathrm{Iwjing229@163.com}$
}

Keywords: Roadway excavation disturbance, Deep mine, Adjacent tunnel, Roadway stability, Numerical simulation.

\begin{abstract}
By using the finite element software ABAQUS, the paper carries out numerical simulation analysis on influence of new coal lane tunneling along the groove disturbing the original high pumping Lane in a deep mine 1112 working face in Huainan. This article analyzes two tunnels in different distance with the new roadway excavation cause position change as well as an increase in the maximum stress and displacement of the original high pumping Lane in deep mine. In this essay, we explore the influence of new roadway excavation to original roadway stability, and study the deep adjacent tunnel excavation disturbance effect to the original roadway stress and strain change. The results show that: the reasonable distance between shallow tunnels is not applicable to deep condition. Meanwhile, the roadway excavation disturbance effect between adjacent tunnels is significantly in deep mine. In addition, the original roadway need to add new support measures on the basis of the existing supporting structure to ensure its normal use.
\end{abstract}

\section{Introduction}

With the booming of economy in our country, the energy consumption is growing up year by year, the demand for coal is increasing, the coal resources in shallow part is tapered, the depth of coal mining is also increasing, most of the mines reaches deep mining[1-3]. The crustal stress in mine roadway is on the rise and some new rock pressure problem gradually emerged along with the increase of mining depth, roadway excavation disturbance is one of them.

Roadway driving disturbance means that the second excavation of roadway disturbs the first one in the process of multiple neighboring roadway arrangement. There are some studies of the roadway stability about different arrangement modes and excavation sequences in the shallow underground engineering [4-7]. In the deep case, the enlargement of stress-concentrated areas on both sides of the roadway leading to stress-concentrated zone superimposed on each other between adjacent tunnel, and the disturbance of second excavation to the first one appeared gradually. When it gets more serious, it can cause the whole deformation of first laneway [8-10]. Existing research focuses on the support principle of neighboring roadway, but the influence of the different spacing of roadway on the stability in the research is less. This thesis regards the tunneling transport gateway of roadway and high pumping tunnel in a deep mine 11-2 coal seam in Huainan mining group as research object, and studies the stability of the two roadways at different pitches. By using the finite element software ABAQUS for numerical simulation, this paper carries out the influence of new roadway tunneling disturbing the original roadway at different pitches in deep mine.

\section{Calculation model and simulation program}

\section{1 Engineering site condition}

The high pumping Lane in a -906m deep mine 1112 working face in Huainan Mining Group has excavated for a long time, the coal lane tunneling along the groove below it starts construction. These 
two roadways are 45 meters apart with the same direction. The two roadways are suitable for research on the effects of roadway excavation disturbance in deep mine, as shown in figure 1.

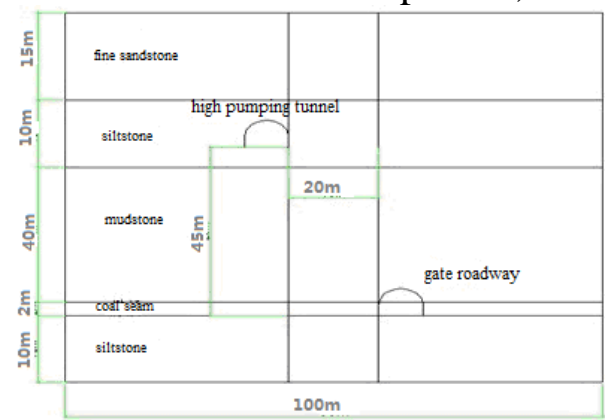

Figure 1 the relative position of two roadways

The mutual distance between adjacent coal roadway in our country design in accordance with "the procedure of rational distribution of protection and supporting in coal roadway" from former Soviet Union. According to this regulations, the reasonable spacing D of two roadways is decided by five factors: span length, the burial depth of the tunnel, the intensity of the surrounding rock, dip angle of rock stratum and intersection angle between the roadway and terrane strike. It calculated according to the following formula:

$$
\mathrm{D}=\left(\mathrm{a}_{1}+\mathrm{a}_{2}\right) \mathrm{K}_{1}
$$

in the type $\mathrm{a}_{1}+\mathrm{a}_{2}$ - the total widths of interactional roadways, $\mathrm{m}$;

$\mathrm{K}_{1}$ - - the interaction coefficient of roadways,

In general, the reasonable distance between two roadways is $20 \sim 40 \mathrm{~m}$, and the spacing of raise and dip roadway concentration area is $15 \sim 30 \mathrm{~m}$. Surrounding rock is stable in small value, and unstable regularly take large value. When the spacing of roadway is greater than reasonable spacing, interaction between two roadways can be neglected. But in the case of deep mining, neighboring roadway influenced by the roadway disturbance, the scope of reasonable spacing as above has been unable to apply. The distance between two tunnels in the text is more than $40 \mathrm{~m}$, but the deformation of high pumping tunnel is increased by coal gate roadway excavation in the actual construction. Therefore, the thesis regards these two roadways as the research object to simulate the influence of different spacing of roadway.

\subsection{Model establishment and parameters}

According to the engineering geological conditions of this mine, the paper builds up analysis model about the stability of high pumping tunnel after coal gate roadway excavation. The rocks of this calculation model choose coal seam, mudstone, siltstone and sandstone. Coal floor can be simplified as siltstone, and the roof shall comprise of mudstone, siltstone and sandstone. The parameters of rock mechanics performance are shown in table 1.

Table 1 the parameters of rock mass mechanics

\begin{tabular}{ccccccccc}
\hline lithology & $\begin{array}{c}\text { bulk } \\
\text { modulus } \\
\text { /Mpa }\end{array}$ & $\begin{array}{c}\text { shear } \\
\text { modulus } \\
\text { /Mpa }\end{array}$ & $\begin{array}{c}\text { cohesive } \\
\text { force } \\
\text { /Mpa }\end{array}$ & $\begin{array}{c}\text { angle of } \\
\text { internal } \\
\text { friction/ }\end{array}$ & $\begin{array}{c}\text { tensile } \\
\text { strength } \\
\text { /Mpa }\end{array}$ & $\begin{array}{c}\text { density } \\
\text { /g/cm3 }\end{array}$ & $\begin{array}{c}\text { elasticity } \\
\text { modulus } \\
\text { /Mpa }\end{array}$ & $\begin{array}{c}\text { poisson } \\
\text { ratio / } \rho\end{array}$ \\
\hline mudstone & 260 & 2465 & 1.33 & 13.8 & 5.41 & 2.82 & 3547 & 0.39 \\
$\begin{array}{c}\text { siltstone } \\
\text { fine }\end{array}$ & 1110 & 3627 & 3.20 & 22.83 & 7.61 & 2.92 & 5846 & 0.22 \\
$\begin{array}{c}\text { sandstone } \\
\text { coal seam }\end{array}$ & 2787 & 8023 & 5.16 & 25.22 & 10.96 & 3.10 & 13484 & 0.19 \\
\hline
\end{tabular}

Simulation using the Mohr-Coulomb model, the form of M-C rule is:

$\tau=c+\sigma_{n} \operatorname{tg} \varphi$

Promote to the general case, also can be written as: 


$$
\frac{\sigma_{1}-\sigma_{3}}{2}=-\frac{\sigma_{1}+\sigma_{3}}{2} \sin \varphi+c \cos \varphi
$$

In this type: c is cohesive force, ${ }^{\varphi}$ is angle of internal friction, $\sigma_{n}$ for the Normal stress in shear plane, $\mathrm{n}$ for outward normal direction in shear plane. We perform the spacing of two roadways in model once every $10 \mathrm{~m}$ for a simulation from $10 \mathrm{~m}$ to $50 \mathrm{~m}$. Comparing the simulation results of the 5 cases, the influence of roadway excavation disturbance to the original roadway stability in different spacing was observed. Model is shown in figure $2[11,12]$.

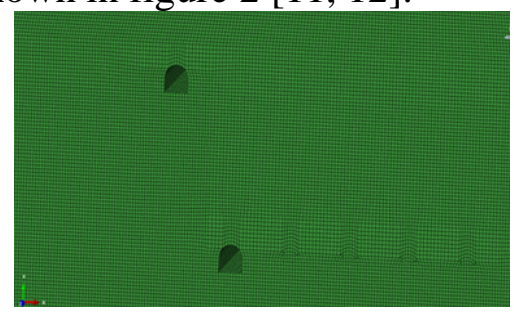

Figure 2 the numerical model

\section{The simulation results analysis}

The stress and displacement of high pumping tunnel in original state are shown in figure 3. It can be seen in the case of - 906m, the pressure on high pumping tunnel is still larger due to the high ground stress. Although the initial support have been proceeded. The position of the maximum vertical stress of surrounding rock in roadway at the bottom of roadside and the maximum value close to $43 \mathrm{Mpa}$, and the maximal displacement position in the roadway floor reaches $25 \mathrm{~mm}$.

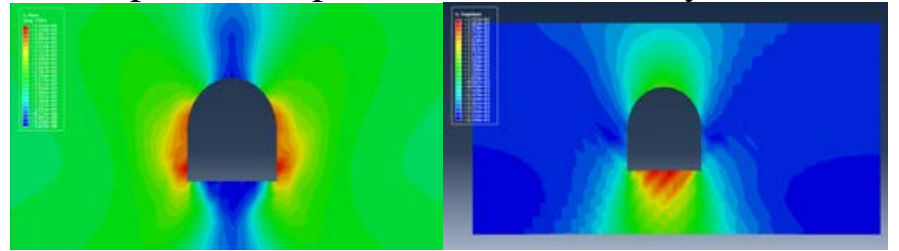

(a)The stress nephogram (b) The displacement nephogram

Figure 3 the stress and displacement nephogram of high pumping tunnel in original state

According to the simulation scheme, the stress and displacement nephogram of high pumping tunnel are shown in figure 4 and 5 respectively when the spacing between coal gate roadway and high pumping tunnel is $10 \mathrm{~m}, 20 \mathrm{~m}, 30 \mathrm{~m}, 40 \mathrm{~m}$ or $50 \mathrm{~m}$. In the figure 4 , the stress distribution of high pumping tunnel have taken place in a certain excursion after the coal roadway excavation because the coal gate roadway locate in the low right of high pumping tunnel. The location of maximum stress happened changes especially in small spacing, and it also led to the position of maximum displacement changes.

Roof convergence becomes the biggest problem of roadway deformation. When the spacing of roadway is $10 \mathrm{~m}$, coal roadway has pressure relief effect on high pumping tunnel. The maximum stress of high pumping tunnel is only 39Mpa less than the maximum stress that coal roadway is not excavated, but it did not affect the increase of maximum displacement. At this time, the maximum displacement of high pumping tunnel turns into $46.8 \mathrm{~mm}$. When the spacing is larger than $20 \mathrm{~m}$, changes of maximum stress and displacement start regularly. The maximum stress and displacement gradually reduced with the increase of spacing. The maximum stress changes from 51Mpa in $20 \mathrm{~m}$ of spacing to $44.8 \mathrm{Mpa}$ in $50 \mathrm{~m}$, all of them are larger than the original state stress of high pumping tunnel. At the same time the maximum displacement changes from $46.8 \mathrm{~mm}$ to $25.8 \mathrm{~mm}$, and it is still larger than the original. Through the simulation, we can see the position of stress in high pumping tunnel has changed and the location of the maximal displacement also changed after coal roadway excavation. The figure 5 reveals that the position of the maximum displacement is located in the roof of high pumping tunnel. When the distance between two tunnels is $50 \mathrm{~m}$, the high pumping tunnel is still affected by the roadway excavation disturbance. The position of the maximal displacement has 
changed significantly, although the maximal displacement and stress did not increase obviously. The original supporting measure in high pumping tunnel can not be applied after coal roadway tunneling. The distance between two tunnels is about $45 \mathrm{~m}$ between $40 \mathrm{~m}$ and $50 \mathrm{~m}$ in practical engineering, the maximum stress and displacement of high pumping tunnel are increased and the position are changed after coal roadway excavation. The original supporting structure needed to add new support pattern in order to guarantee the high pumping tunnel exploit successfully.

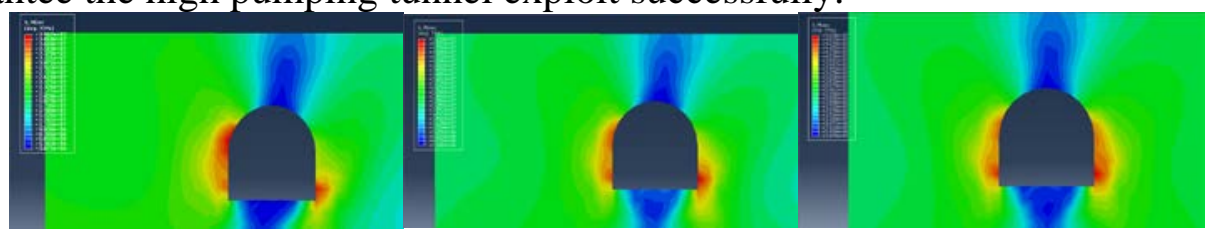

(a)10m spacing

(b)20m spacing

(c)30m spacing

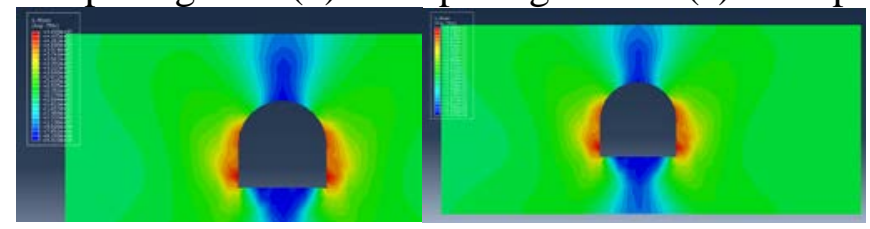

(d) $40 \mathrm{~m}$ spacing

(e) $50 \mathrm{~m}$ spacing

Figure 4 the nephogram of high pumping tunnel stress after coal roadway excavation

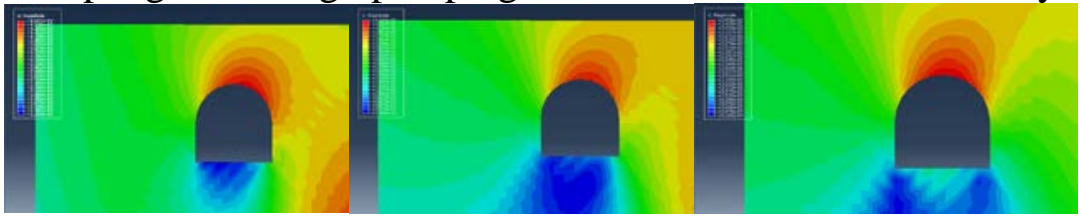

(a)10m spacing

(b)20m spacing

(c)30m spacing

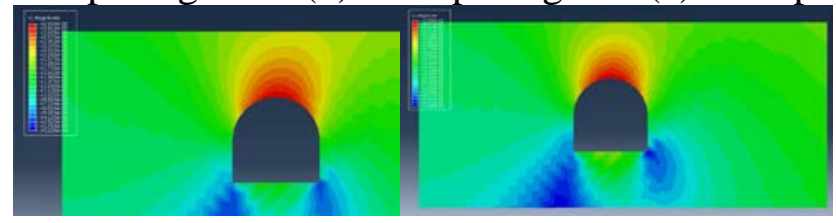

(d) 40m spacing

(e) $50 \mathrm{~m}$ spacing

Figure 5 the nephogram of high pumping tunnel displacement after coal roadway excavation

\section{Summary}

1) The roadway excavation disturbance effect between adjacent tunnels is obvious in the deep mine. For this reason, the original reasonable spacing of roadway no longer applies in deep mine. The original roadway supporting measures should be adjusted to ensure that the tunnel can be used under the action of new roadway excavation disturbance.

2) Based on the results of numerical simulation, the different location of the new tunnel will lead to value increased and the position changed in maximum stress and maximum deformation of original roadway. When the distance between two tunnels reaches $50 \mathrm{~m}$, the effect of roadway excavation disturbance begins to abate and maximum deformation does not increase obviously. However, the changes in the location of maximum displacement will still lead to instability of the original supporting structure of roadway.

3) Numerical simulation methods effectively consider the complex geological conditions and construction factors and the results from that are more close to the engineering practice. Make full use of the results from numerical simulation can predict the possibility of stress and deformation of roadway, therefore, corresponding supporting measures can be formulated in advance to avoid the destruction of the roadway and delay of the project. 


\section{References}

[1]HE Manchao, XIE Heping, PENG Suping, et al. Study on rock mechanics in deep mining engineering $[\mathrm{J}]$. Chinese Journal of Rock Mechanics and Engineering, 2005 , 24(16) : 2803-2813.

[2] ZHOU Hongwei, XIE Heping, ZUO Jianping. Developments in researches on mechanical behaviors of rocks under the condition of high ground pressure in the depths[J]. Advances in Mechanics, 2005, 35(1): 191-199.

[3] HE Yongnian, HAN Lijun, SHAO Peng, et al. Some problems of rock mechanics for roadways stability in depth[J]. Journal of China University of Mining \&Technology, 2006, 35(3): 288-295.

[4] CHEN Weizhong,LI Shucai, ZHU Weishen,et al. Excavation and optimization theory for giant underground caverns constructed in high dipping laminar strata $[\mathrm{J}]$. Chinese Journal of Rock Mechanics and Engineering, 2004, 23(19) : 3281-3287.

[5] YU Weiping, GENG Keqin, WANG Xiaogang. Stability analysis of surrounding rock of underground openings of a hydropower station [J] . Rock and Soil Mechanics, 2004, 25(12) : 1955-1960.

[6]Liu, H.Y, Small J.C., Carter J.P. Full 3D modelling for effects of tunnelling on existing support systems in the Sydney region[J].Tunneling and Underground Space Technology. 2008,4: 399-420.

[7] LIU Quansheng, SHI Kai, HUANG Xing. Analysis on site monitoring of roadway under disturbed effects by excavation of neighboring roadways[J]. Journal of China Coal Society. 2011,36(6):897-902.

[8] HE Manchao, LI Guofeng, REN Aiwu, et al. Analysis of the Stability of Intersecting Chambers in Deep Soft-Rock Roadway Construction[J]. Journal of China University of Mining \& Technology,2008,37(2):167-170.

[9] KANG Hongpu, LIN Jian, YANG Jinghe, et al. Stress distribution and synthetic reinforcing technology for chamber group with soft and fractured surrounding rock[J]. Chinese Journal of Geotechnical Engineering , 2011, 33(5):808-814.

[10] WANG Qizhou,XIE Wenbing, JING Shengguo, et. Instability mechanism and control technology of chamber group surrounding rock in complex structural area[J]. Journal of Mining \& Safety Engineering ,2014,3(2):263-269.

[11] LI Guichen, ZHANG Nong, WANG Cheng, et al. Optimizing the section shape of roadways in high stress ground by numerical simulation[J]. Journal of China University of Mining \& Technology, 2010, 39(5): 652-658.

[12] MENG Qingbin, HAN Lijun, QIAO Weiguo, et al. Numerical Simulation of Cross-Section Shape Optimization Design of Deep Soft Rock Roadway Under High Stress[J]. Journal of Mining \& Safety Engineering, 2012, 29(5): 650-656. 